\title{
Low Frequency Electromagnetic Casting of 2195 Aluminum-Lithium Alloy and Its Effects on Microstructure and Mechanical Properties
}

\author{
Fu-Yue Wang ${ }^{1} \cdot$ Xiang-Jie Wang $^{1} \cdot$ Wei Sun $^{1} \cdot$ Fang Yu $^{1} \cdot$ Jian-Zhong Cui ${ }^{1}$ \\ Received: 28 August 2019 / Revised: 10 October 2019 / Published online: 20 January 2020 \\ (C) The Chinese Society for Metals (CSM) and Springer-Verlag GmbH Germany, part of Springer Nature 2020
}

\begin{abstract}
In this study, the low frequency electromagnetic casting (LFEC) technology was adopted to fabricate $2195 \mathrm{Al}-\mathrm{Li}$ alloy. The microstructure and solid solubility of as-cast 2195 alloys, as well as the second phase precipitation and tensile properties after aging, were investiagated and compared with the counterpart direct chill casting 2195 alloy. Our results indicate that LFEC can significantly improve the microstructure and metallurgical quality of as-cast alloy, and increase the number density of $\theta^{\prime}$ $\left(\mathrm{Al}_{2} \mathrm{Cu}\right)$ and $T_{1}\left(\mathrm{Al}_{2} \mathrm{CuLi}\right)$ phases during aging treatment due to the enhanced solubilities of alloying elements. The tensile properties of 2195 aged alloy cast by LFEC were hence improved evidently.
\end{abstract}

Keywords LFEC (low frequency electromagnetic casting) $\cdot 2195$ Aluminum-lithium alloy $\cdot$ Casting defects · Microstructure $\cdot$ Tensile property

\section{Introduction}

$\mathrm{Al}-\mathrm{Li}$ alloys, especially the $\mathrm{Al}-\mathrm{Cu}-\mathrm{Li}$ alloys, alloys are widely applied for aerospace industries due to their good combination of low density, high elastic modulus, high specific strength and specific stiffness [1,2]. The most important prerequisite for acquiring a high performance of aluminum-lithium alloy products is the production of a high metallurgical quality casting ingots. However, conventional direct chill casting (DCC) process would cause a series of casting defects in aluminum-lithium alloy ingots such as oxide inclusions, porosity, coarse grains, and serious segregation of alloying element at grain boundaries. These unfavorable facts limited the applications and development of aluminum-lithium alloys [3, 4]. The molten aluminum-lithium alloys are extremely easy to be oxidized and the melt is prone to absorb hydrogen, [5]. In addition, lots of eutectic

Available online at http://link.springer.com/journal/40195.

Xiang-Jie Wang

wangxj@epm.neu.edu.cn

Fu-Yue Wang

NEUWFY@ sina.com

1 Key Lab of Electromagnetic Processing of Materials, Ministry of Education, Northeastern University, Shenyang 110819, China structures of $\mathrm{Al}, \mathrm{Cu}, \mathrm{Mg} \mathrm{Ag}$ and $\mathrm{Li}$ form at grain boundaries during non-equilibrium solidification [6], as a consequence of serious grain boundary segregation. These can cause a sharp deterioration in strength and toughness of the alloy. For that matter, electromagnetic casting methods have been introduced to weaken the influence of grain boundary segregation, for example, Zhang [7] and Wang et al. [8] have obtained high solid solubility as-cast aluminum alloy ingots by refining and electromagnetic process (CREM) and electromagnetic casting (EMC), respectively. But these studies have no quantitative analysis on the solid solubility of alloying elements.

Meanwhile, a more effective and pollution-free casting technology, low frequency electromagnetic casting (LFEC), was proposed and researched by Cui and his team [9]. LFEC is carried out by using a lower frequency than that in the casting, refining and electromagnetic process (CREM) proposed by Vives [10]. The flow and temperature distribution of melt in the sump are improved by LFEC. In recent years, we have seen a growing interest in the production of magnesium alloy and aluminum alloys by LFEC owing to a series of characteristics and advantages, such as refined microstructure, improved surface quality of ingots, improved macrosegregation, eliminating cracks and increased intra-granular solid solubility of alloy elements [11-14], which are all the key aspects to prepare the high quality aluminum-lithium 
alloy ingots. But, so far, there are few reports on the casting technology of aluminum-lithium alloys.

In this study, the 2195 aluminum-lithium alloy ingots were cast by DCC and LFEC, and then prepared into cylindrical bars under the same conditions of extrusion process and heat treatments. To explore the effects of LFEC on the microstructure, intra-granular solid solubility of alloy elements, and tensile properties of 2195 aluminum-lithium alloy. Ultimately, an efficient method and optimized parameters of LFEC were given to prepare of high-quality 2195 aluminum-lithium alloy ingots.

\section{Experimental}

\subsection{Alloy Preparation}

The Al (99.9\%), Mg (99.9\%), Ag particle (99.99\%) Li $(99.9 \%)$, and the master alloys of $\mathrm{Al}-20 \mathrm{Cu}, \mathrm{Al}-3 \mathrm{Zr}$, A1-5Ti-B were chosen as the raw materials. The chemical composition of 2195 alloy and analyzed composition of as-cast alloy ingots detected using ICP, shown in Table 1.

The preparation of ingots could be divided into two steps: smelting and casting. The smelting was implemented by a $10 \mathrm{~kW}$ electrical resistance furnace with a stainless crucible. When the temperature of molten alloy kept at $700{ }^{\circ} \mathrm{C}$ steadily, the smelting was completed and the casting was ready to begin. The molten alloy was moved into the crystallizer mold through the hot top at $700{ }^{\circ} \mathrm{C}$ before being cast into ingots with a diameter of $125 \mathrm{~mm}$ at a cooling water of 45 $\mathrm{L} / \mathrm{min}$ and at a casting velocity of $125 \mathrm{~mm} / \mathrm{min}$. Meanwhile, the LFEC device had been turned on. During the casting process the frequency of low frequency electromagnetic field would remain unchanged at $10 \mathrm{~Hz}$ and $20 \mathrm{~Hz}$ and the current intensity of low frequency electromagnetic field would change from $0 \mathrm{~A}$ (DCC), to $50 \mathrm{~A}$, to $100 \mathrm{~A}$, to $150 \mathrm{~A}$. The low frequency electromagnetic field was implemented by a 100 turns coil arranged outside the mold. A graphite ring was set in the crystallizer mold, and the calcium silicate hot top with a $\mathrm{SiC}$ coating was embedded above the graphite ring for reducing the heat loss of melt. The equipment of LFEC schematically is shown in Fig. 1.

All of the ingots were homogenizing heat treated at 505 ${ }^{\circ} \mathrm{C}$ for $20 \mathrm{~h}$. The surfaces of about $8 \mathrm{~mm}$ of the ingots were removed, and then were extruded at $400{ }^{\circ} \mathrm{C}$ into bars with a radius of $16 \mathrm{~mm}$ at an extrusion ratio of 15 . These bars were solid solution heat treated at $505{ }^{\circ} \mathrm{C}$ for one hour and

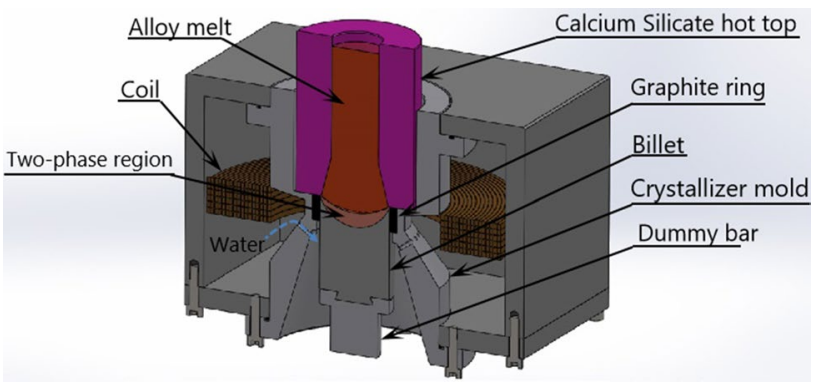

Fig. 1 Schematic illustration of the low frequency electromagnetic casting

quenched into cold water immediately. Finally aging heat treated at $150{ }^{\circ} \mathrm{C}$ for $30 \mathrm{~h}$ (T6 treatment). As shown in Fig. 2, samples for microstructure observation and tensile test were taken from different positions in the ingot.

\subsection{Characterizations and Testing}

In this research, the effects of LFEC on the microstructure, intra-granular solid solubility of alloy elements, and tensile properties of 2195 aluminum-lithium alloy were investigated by using an optical microscope (OM), a scanning acoustic microscope (SAM), a transmission electron microscope (TEM), an inductively-coupled plasma atomic emission spectroscope (ICP), a differential scan calorimeter (DSC), an X-ray diffraction meter (XRD), an electron probe micro analyzer (EMPA), and a tensile testing machine. The as-cast samples for microstructure observation were observed by a Leica optical microscope. Samples for SAM with $20 \mathrm{~mm}$ thickness were scanned by a KSI scanning acoustic microscope with $50 \mathrm{MHz}$. The white spots (casting defects) in the SAM photos were measured and counted by Image-Pro Plus. The element mappings and the casting defects of the as-cast samples were determined by JXA-8530 electron probe micro analyzer. TEM observation was conducted on a Tecnai $\mathrm{G}^{2} 20$ transmission electron micro-scope operating at $200 \mathrm{kV}$. The samples for TEM observation were mechanically thinned and twin-jet polishing thinned to 50-80 $\mu \mathrm{m}$. The number density and length of $T_{1}$ phase and $\theta^{\prime}$ phase were measured from four TEM photos by Image-Pro Plus. The DSC tests were carried out by a Netzsch 404F3 differential scanning calorimeter with a heating rate of $10^{\circ} \mathrm{C} / \mathrm{min}$ from 25 to $600{ }^{\circ} \mathrm{C}$. The XRD tests were implemented by a 3064 XPERT-Pro X-ray diffraction meter with a scanning step length of $0.02^{\circ}$, the scanning ranged from $5^{\circ}$ to $90^{\circ}$.
Table 1 Nominal and analyzed compositions of a 2195 alloy (wt\%)

\begin{tabular}{llllllllll}
\hline Element & $\mathrm{Cu}$ & $\mathrm{Li}$ & $\mathrm{Mg}$ & $\mathrm{Ag}$ & $\mathrm{Zr}$ & $\mathrm{Ti}$ & $\mathrm{Fe}$ & $\mathrm{Si}$ & $\mathrm{Al}$ \\
\hline Nominal & $3.70-4.30$ & $0.80-1.20$ & $0.25-0.80$ & $0.25-0.60$ & $0.08-0.16$ & - & $<0.10$ & $<0.10$ & $\mathrm{Bal}$ \\
Analyzed & $4.15-4.26$ & $1.08-1.15$ & $0.38-0.45$ & $0.39-0.41$ & $0.12-0.13$ & 0.05 & $<0.08$ & $<0.04$ & $\mathrm{Bal}$ \\
\hline
\end{tabular}




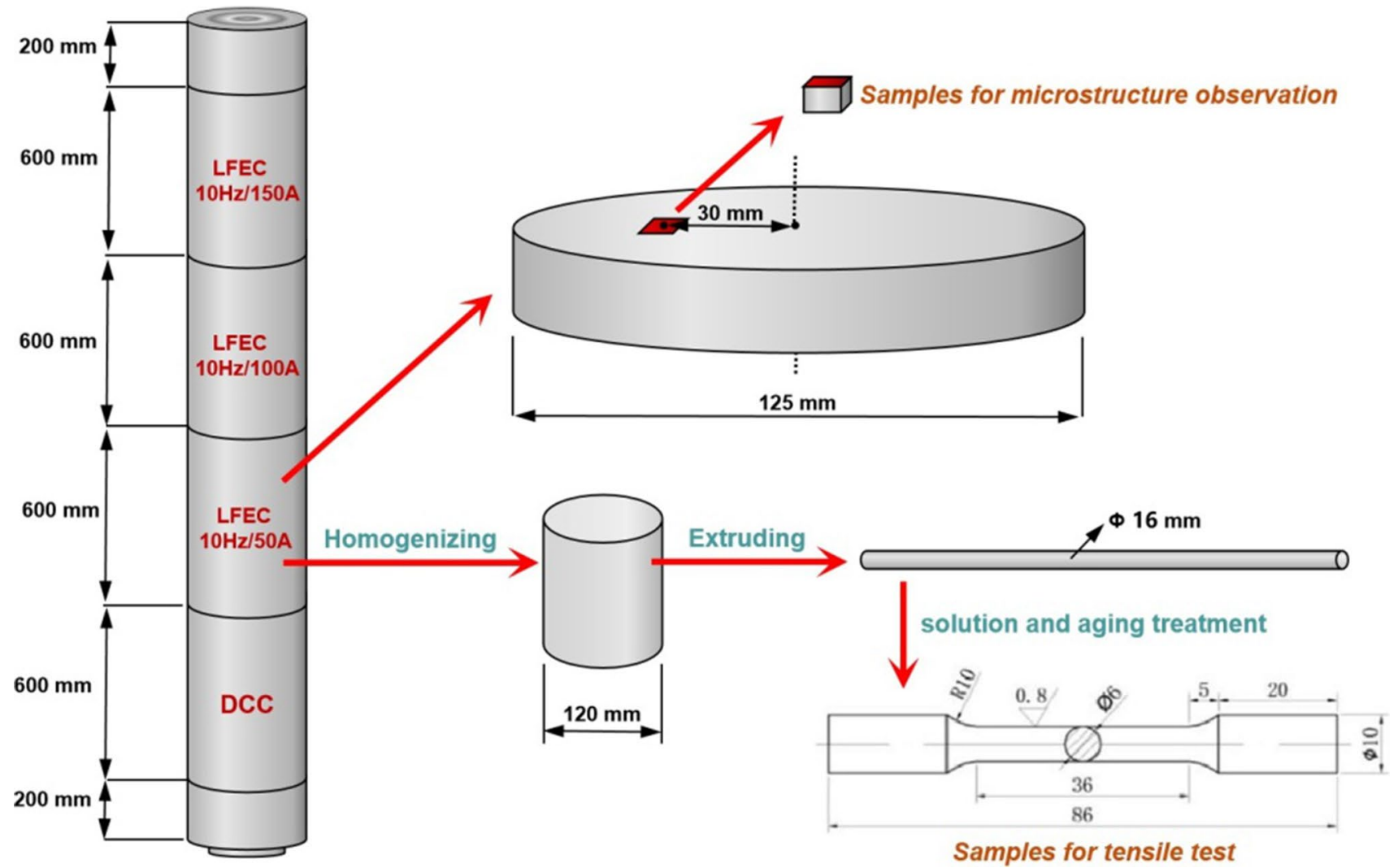

Fig. 2 Schematic illustration of samples for microstructure observation and tensile test

The alloy bars after aging heat treatment were machined into standard tensile samples. Tensile tests were implemented by an AG-IS testing machiner with a strain rate of $2.0 \mathrm{~mm} / \mathrm{min}$. The tensile tests were repeated four times for each casting condition, finally the yield strength, ultimate tensile strength, and elongation were acquired.

\section{Results and Discussion}

\subsection{Effects of LFEC on Microstructure of 2195 As-Cast Alloys}

The microstructure of 2195 as-cast alloys cast by DCC and LFEC are shown in Fig. 3. The grain sizes of 2195 as-cast alloys are shown in Fig. 4. In the case of DCC, grains were mainly consisted of coarse rose-shape dendrites with a grain size of $219 \mu \mathrm{m}$. The grain size decreased significantly with the increasing current intensity at both $10 \mathrm{~Hz}$ and $20 \mathrm{~Hz}$. When frequency is $20 \mathrm{~Hz}$, the grain sizes decrease from $199 \mu \mathrm{m}$ at $50 \mathrm{~A}$ to $151 \mu \mathrm{m}$ at $150 \mathrm{~A}$. When frequency is $10 \mathrm{~Hz}$, the grain sizes decrease from $197 \mu \mathrm{m}$ at $50 \mathrm{~A}$ to $115 \mu \mathrm{m}$ at $150 \mathrm{~A}$. When the current intensity of electromagnetic is set at $50 \mathrm{~A}$ with two frequencies, only minor variation is observed, as shown in Fig. 3b, c.
When the current intensity of LFEC increases to $100 \mathrm{~A}$ at two frequencies, a mixed microstructure containing coarse and fine grains is observed, as shown in Fig. 3d, e. On further increasing the current intensity to $150 \mathrm{~A}$, coarsedendritic grains disappear and a large number of more refined grains are observed. No significant differences are observed between 10 and $20 \mathrm{~Hz}$. However, the grain sizes decrease remarkably when applying LFEC with $10 \mathrm{~Hz} / 150$ A, as illustrated in Fig. 3f.

Grain refinement is of great significance for improving the mechanical properties of aluminum alloys. For 2195 alloy, the refinement of grain causes the increase of grain boundaries, which not only acts as obstacles to dislocation motion [15], but also benefits nucleation for the precipitates during aging treatment [16]. The mechanism of grain refinement under low frequency electromagnetic field has been systematically and extensively investigated in previous research $[13,16]$. In LFEC treatment, the melt in the sump was acted upon by the Lorenz forces produced by the interaction of the induced current and electromagnetic field. The Lorentz force is written as [17]:

$F=\frac{1}{\mu}(B \cdot \nabla) B-\frac{1}{2 \mu} \nabla B^{2}$, 

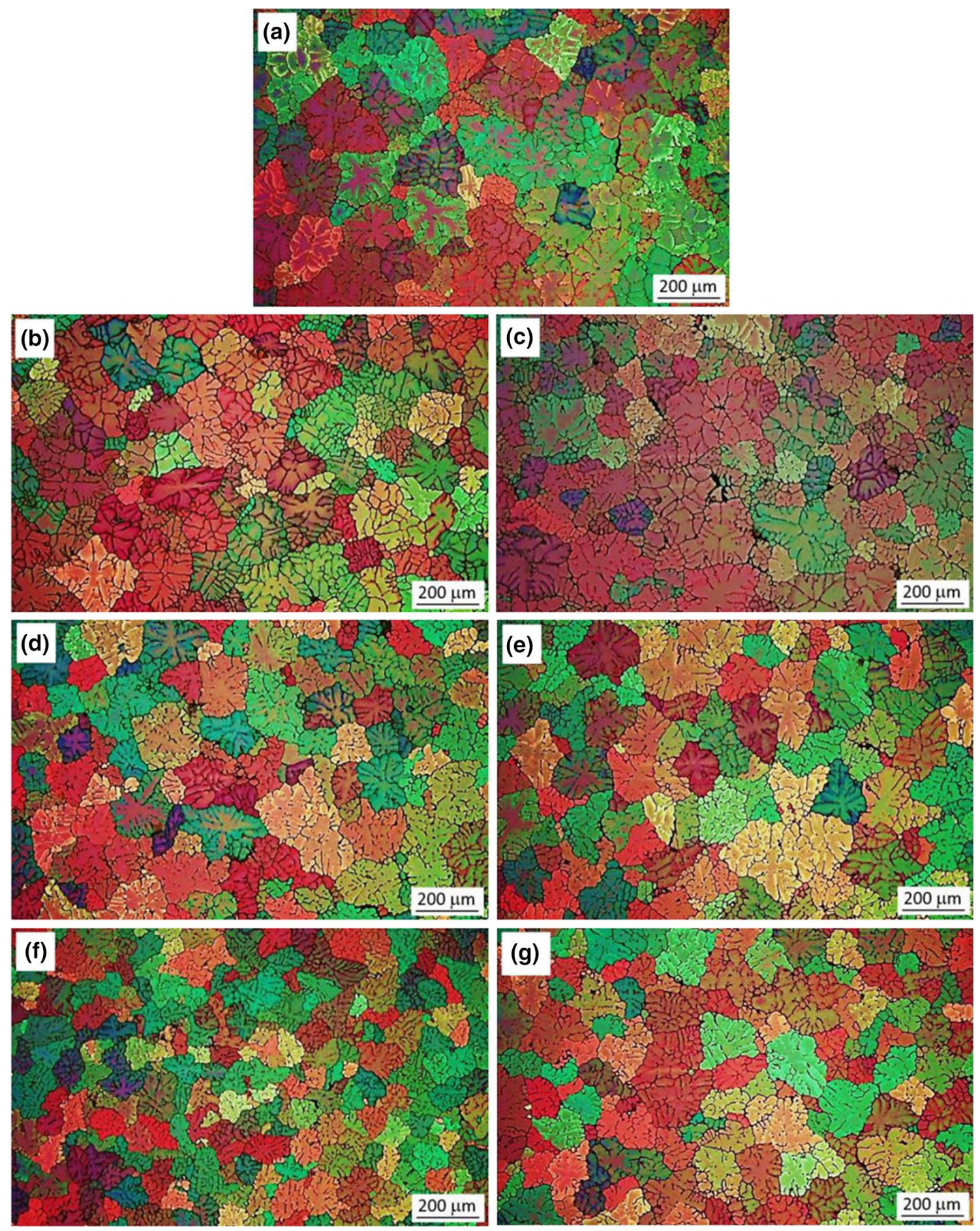

Fig. 3 Microstructures of 2195 as-cast alloys cast by the different electromagnetic conditions: a DCC; b LFEC with 50 A/10 Hz; c LFEC with $50 \mathrm{~A} / 20 \mathrm{~Hz}$; d LFEC with $100 \mathrm{~A} / 10 \mathrm{~Hz}$; e LFEC with $100 \mathrm{~A} / 20 \mathrm{~Hz} ; \mathbf{f}$ LFEC with $150 \mathrm{~A} / 10 \mathrm{~Hz} ; \mathbf{g}$ LFEC with $150 \mathrm{~A} / 20 \mathrm{~Hz}$

where $B$ is the magnetic induction intensity, $\mu$ is the permeability of the melt. The first term on the right hand of Eq. (1) is the rotary force which is used to stir the molten in the sump; the second item is the potential force which would be balanced by a pressure gradient of liquid. The characteristic length $\delta$, which shows the deceased of the degree of magnetic field as a function of distance into the liquid metal, is the skin depth: 


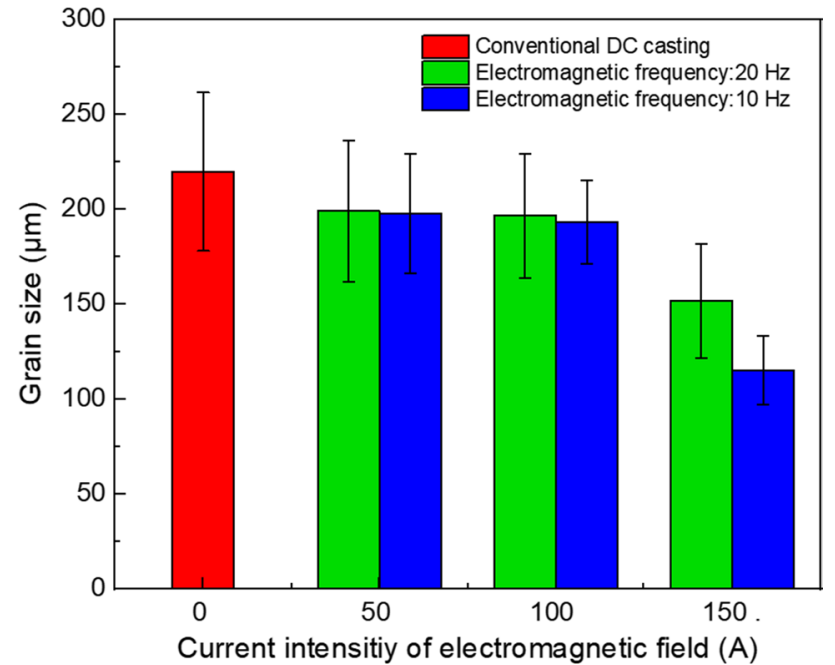

Fig. 4 Grain sizes of 2195 as-cast alloys by DCC and LFEC

$\delta=\sqrt{\frac{1}{\sigma \mu \pi f}}$,

where $\sigma, \mu$, and $f$ are the conductivity, permeability of the melt and the frequency respectively. According to Eq. (2), at constant electromagnetic field intensity, the lower the frequency of electromagnetic field, the higher the electromagnetic intensity in the sump, so as to be obtained a more powerful stir in the sump [17].

The powerful vortex stir caused by the Lorentz force accelerates the melt exchange between the internal and external of the sump as well as intensifies the heat transfer at graphite ring [18], which will reduce shallow liquid sump depth and temperature gradient as shown in Fig. 5. The forced convection makes the heat of melt be extracted faster along the solidification front, the temperature of the melt become more uniform [19]. In such this condition, a large undercooling of the liquid alloy would be acquired in the sump, which leads to a larger number of nucleation. The forced flow of melt caused by vortex stir along the solidification front inhibits the dendrite development by scouring the dendritic tip. Moreover, the application of electromagnetic field to dendrites led to an increase in dendrite fragmentation rate, the dendrites are broken off from the dendritic tip and taken into the sump by the fast-flowing melt, eventually form nuclei for nucleation [20]. The nucleation comes up nearly simultaneously in the sump, and the nuclei collide with each other, which is conducive to get fine grains [19]. As the above results, the microstructure of 2195 as-cast ingots cast by LFEC is finer than that of DCC ingot. At constant current intensity of electromagnetic field, the lower frequency of electromagnetic field could enhance the depth of penetration of electromagnetic field so the effect on grain refining is different under different frequencies of electromagnetic field.

\subsection{Effects of LFEC on Casting Defects of 2195 As-Cast Alloys}

The casting defects in the cross sections of the ingot prepare by DCC and LFEC are scanned and recognized by scanning acoustic microscope. In the photos, it could be clearly seen the number and distribution of defects (white bright spots). The most of casting defects exist in the borber region of

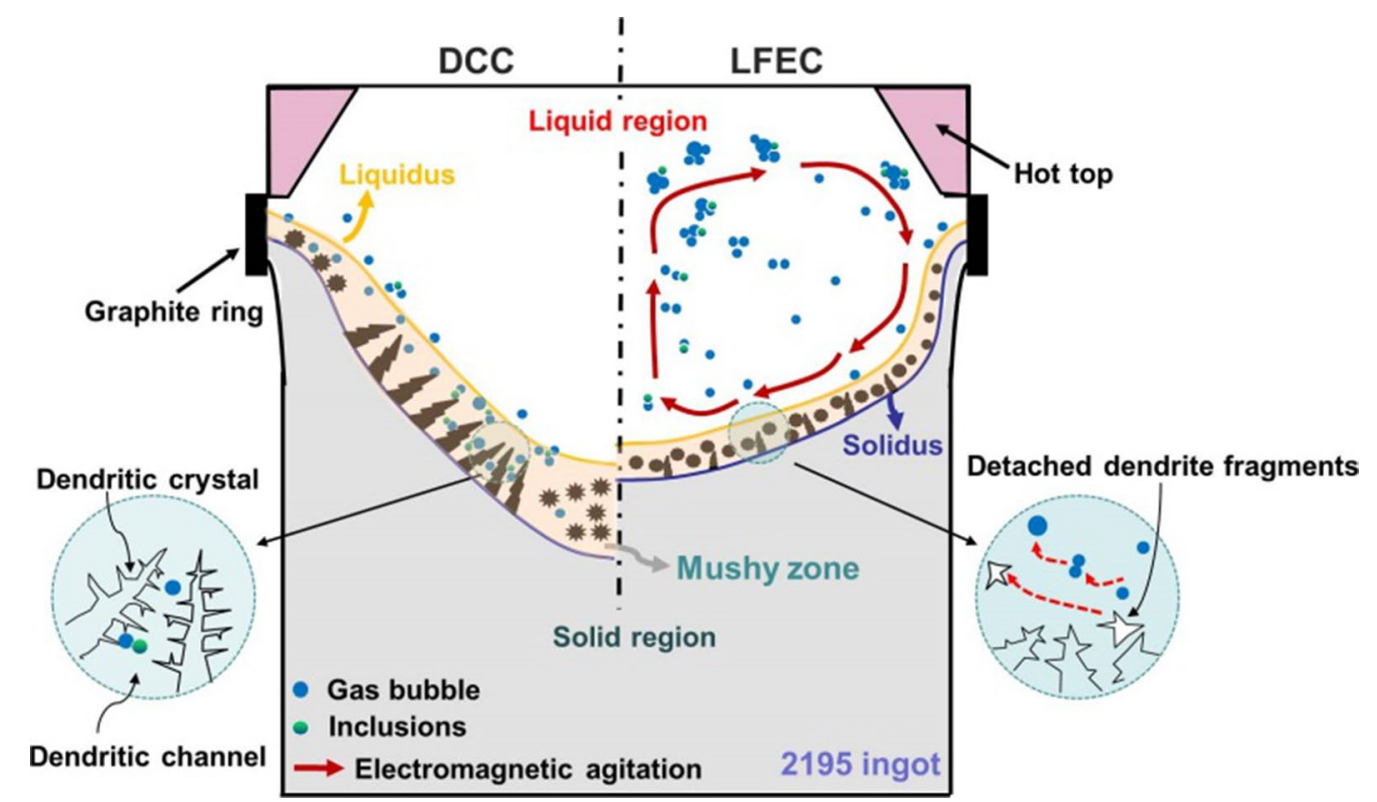

Fig. 5 Schematic diagram to compare the solidification features of DCC and LFEC 
ingots, where is the initial shell region of ingots. The intensified heat transfer nearby graphite ring and the forced melt in the sump during LFEC result in the reduced thickness of initial shell and the casting defects gather in there. This region would have been revomed after homogenizing treatment. It is obvious from Fig. 6 that areal fraction and number of casting defects of 2195 ingot cast by DCC is much more than that by LFEC with $150 \mathrm{~A} / 10 \mathrm{~Hz}$. The casting defects are randomly distributed in the cross section of the ingot cast by DCC, while a small amount of the defects are concentrated in the center of the ingot cast by LFEC with $150 \mathrm{~A} / 10 \mathrm{~Hz}$. The areal fraction and number of casting defects are counted and the results are shown in Table 2.

Further, the casting defects and alloy elements distribution of as-cast alloys were characterized by EMPA. The casting defects including porous structure and inclusions, are shown in Fig. 7a, and the bone rod shaped eutectic phases in-homogeneously and disorderly distributed at grain boundaries. While the defects are found in the ingot cast by LFEC with $10 \mathrm{~Hz} / 150 \mathrm{~A}$ as shown in Fig. 8a, the eutectic phases become into fishing net shape, in which $\mathrm{Cu}, \mathrm{Mg}$ and $\mathrm{Ag}$ are concentrated together and segregated at grain boundaries.

Table 3 shows the EDS analysis of points A and B in Fig. 7a. It can be inferred that Point $\mathrm{A}$ is a $\mathrm{SiC}$ particle which came from the coating to protect corrosion of the calcium silicate hot top, and B is an oxide inclusion. It is clear that the almost simultaneous appearance of looseness, oxide and non-metallic inclusions at grain boundaries.

The molten aluminum-lithium alloys tend to react with $\mathrm{H}_{2} \mathrm{O}$ in the atmosphere, and absorb the hydrogen decomposed from $\mathrm{H}_{2} \mathrm{O}$. The solubility of the hydrogen in molten aluminum-lithium alloy increases dramatically. The hydrogen cannot accomplish a rapid excretion and be caught
Table 2 Casting defects measured in the SAM images of 2195 ingots

\begin{tabular}{lll}
\hline Casting condition & $\begin{array}{l}\text { Areal fraction of cast- } \\
\text { ing defects }(\%)\end{array}$ & $\begin{array}{l}\text { Number } \\
\text { of casting } \\
\text { defects }\end{array}$ \\
\hline DCC & 0.97 & 149 \\
LFEC with $150 \mathrm{~A} / 10 \mathrm{~Hz}$ & 0.08 & 19.0 \\
\hline
\end{tabular}

into dendritic channels due to the poor fluidity at mushy zone during DCC process. Furthermore, the molten aluminum-lithium alloys are liable to oxidize under the atmospheric conditions or unfavorable protection. The loose and porous oxides provide storage space for the hydrogen. It results in forming a symbiosis of inclusion and gas at the terminal stages of solidification. These casting defects cannot be eliminated by heat treatment and extrusion treatment and they would be retained in the ingots, which would induce the micro-cracks and result in deteriorating the mechanical properties of alloys. Nevertheless, when a low frequency electromagnetic field is applied, the melt is stirred by the strong Lorenz forces so the gases have plenty of opportunities to collide with each other, coalesce and grow [21]. Finally, the symbiosis of inclusion and gas would take away from the solidification front with the fast-flowing melt as shown in Fig. 5.

\subsection{Effects of LFEC on Intra-granular Solid Solubility of Alloy Elements of 2195 As-Cast Alloys}

The alloy elements have two forms in as-cast alloy, one of which is forming solid solution or precipitates with intragranulars, the other of which is forming non-equilibrium
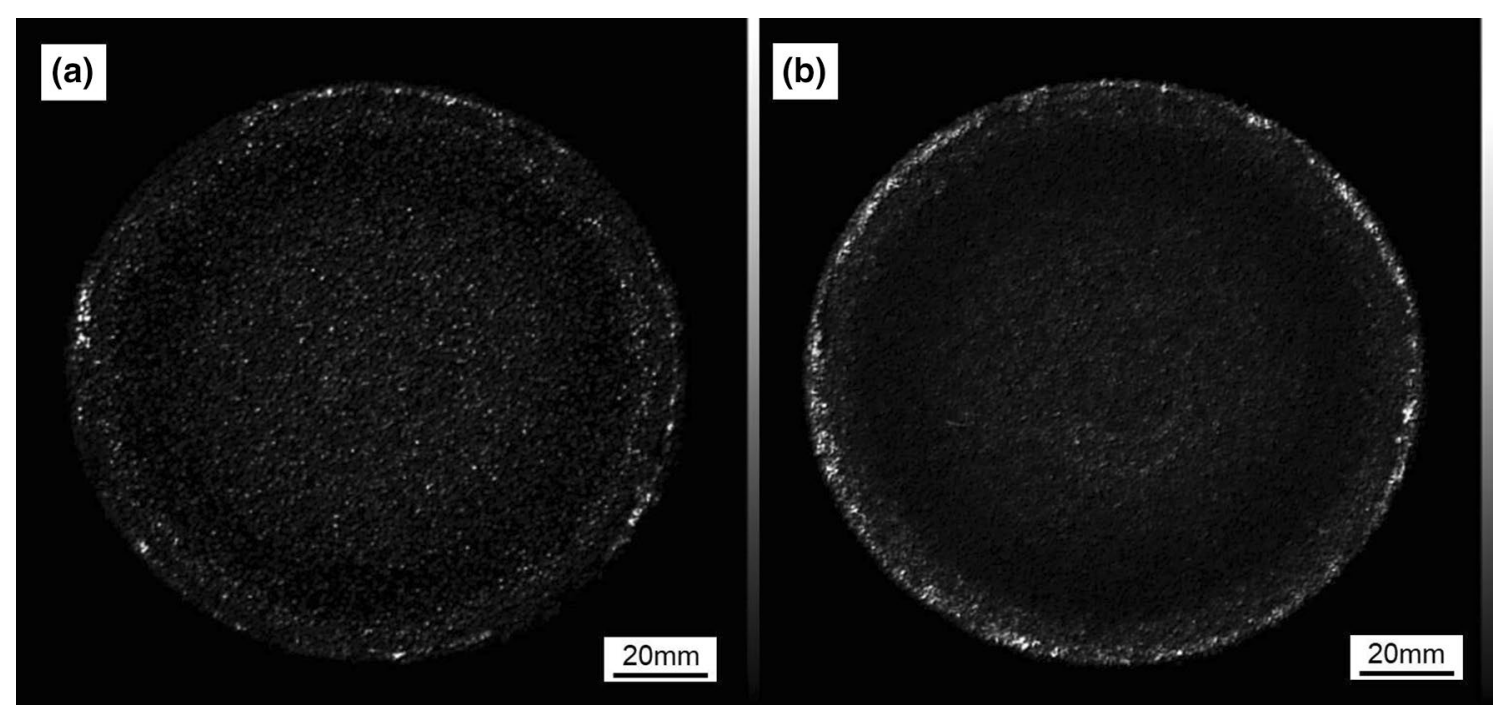

Fig. 6 Scanning acoustic microscope images of 2195 ingots by DCC and LFEC with $10 \mathrm{~Hz} / 150 \mathrm{~A}$ 

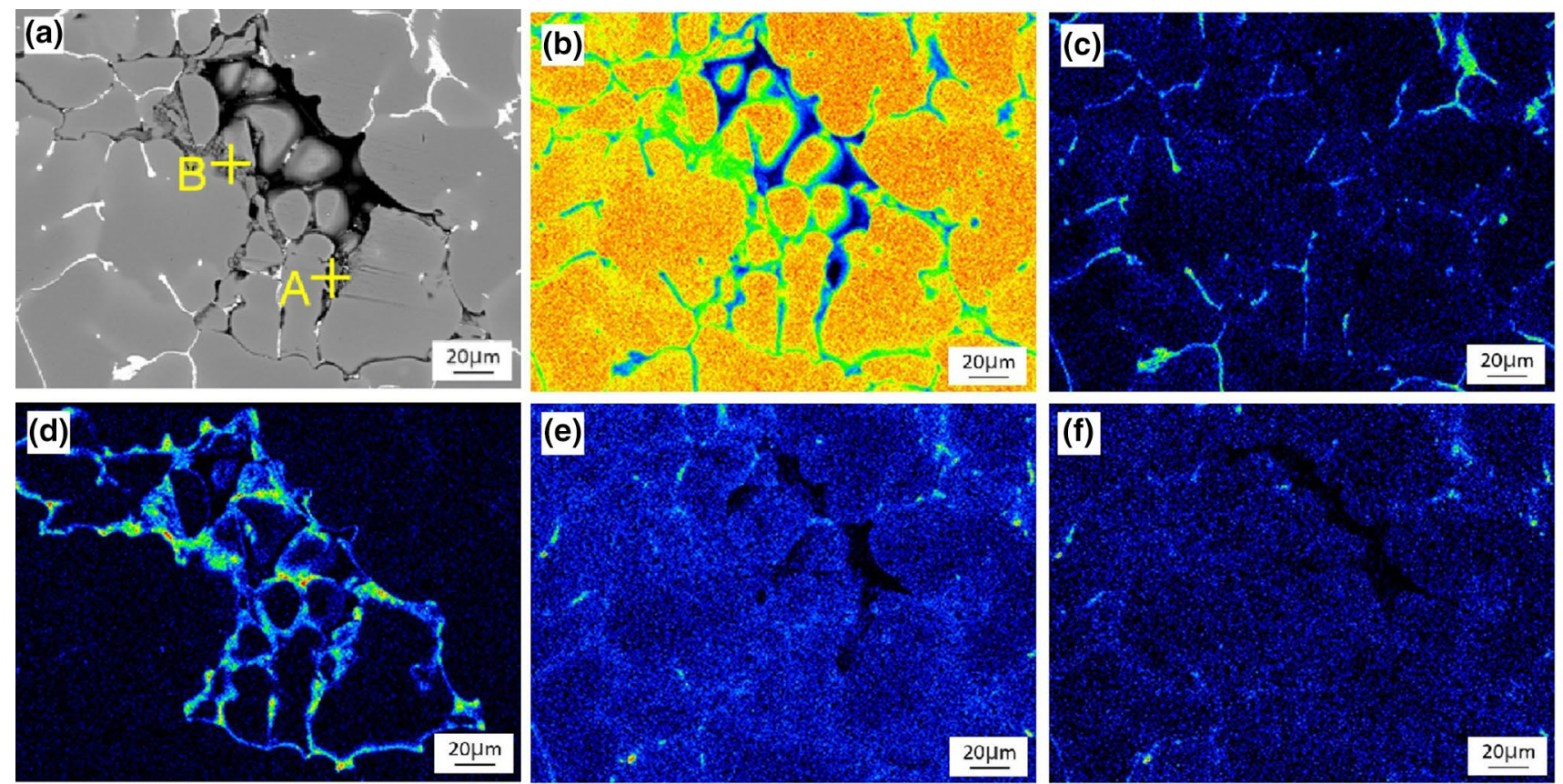

Fig. 7 Element distribution of 2195 as-cast alloy by DCC a SEM microstruture of as-cast alloys; b Al; $\mathbf{c ~ C u ; ~ d ~ O ; ~ e ~ M g ; ~ f ~ A g ~}$
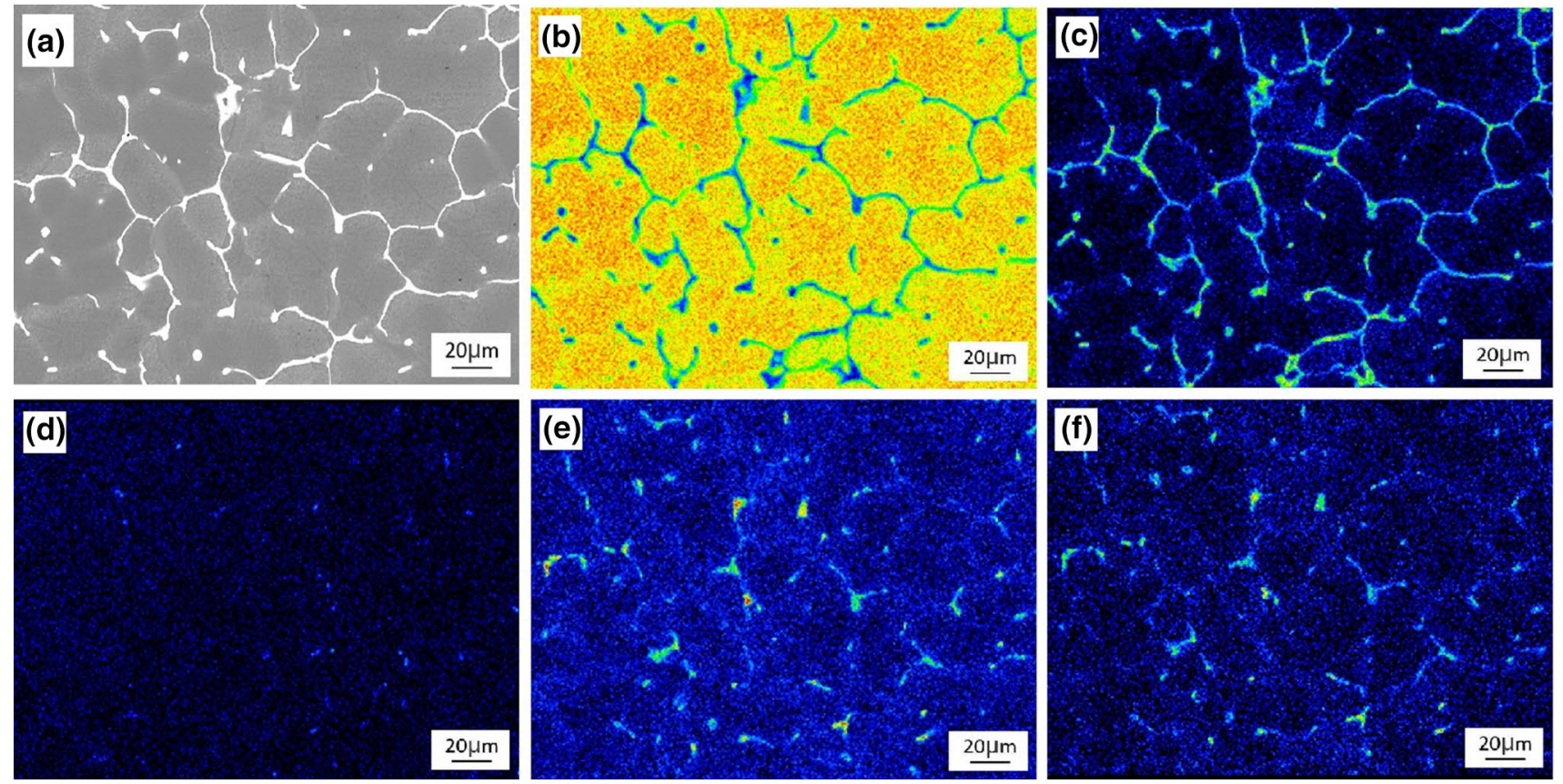

Fig. 8 Element distribution of 2195 as-cast alloy by LFEC with $150 \mathrm{~A} / 10 \mathrm{~Hz}$ a SEM microstruture of as-cast alloys; b $\mathrm{Al} ; \mathbf{c} \mathrm{Cu} ; \mathbf{d ~ O}$; e Mg; f Ag

Table 3 EDS analysis of chemical compositions of as-cast alloys in Fig. 7(a) (mole fraction\%)

\begin{tabular}{llllllr}
\hline Element & $\mathrm{Al}$ & $\mathrm{Cu}$ & $\mathrm{O}$ & $\mathrm{Fe}$ & $\mathrm{C}$ & \multicolumn{1}{c}{$\mathrm{Si}$} \\
\hline Point A & 0.55 & - & 2.59 & - & 45.7 & 51.09 \\
Point B & 65.52 & 3.95 & 14.95 & 1.53 & 3.65 & 1.06 \\
\hline
\end{tabular}


eutectic phase along grain boundaries. A relatively high intra-granular solid solubility of alloy elements is beneficial for the precipitation strengthening and the solution strengthening. On the contrary, the coarse eutectic phases are apt to form the coarse precipitates after the aging treatment. Microcracks will form around these coarse precipitates under the action of a tensile stress. In this section we will describe the change of solid solubility of alloy elements of 2195 as-cast alloys in the different electromagnetic casting conditions from the aspects of thermodynamics and crystallography.

From the point of view of thermodynamics, the remelting of eutectic phases at grain boundary accompanies with the change of the enthalpy [22], it can be exhibited and analyzed by differential scanning calorimetry (DSC) measurement. The results of DSC test of 2195 as-cast alloys cast by DCC and LFEC are shown in Fig. 9.

As can be seen from Fig. 9, the outline of the DSC curves has hardly changed, which illustrates that the type of the eutectic phases of 2195 as-cast alloys has nearly no change after the application of LFEC. The enthalpy $(\Delta H)$ of remelting of eutectic phases can be measured by integrating the area of the DSC curves, and the amount of the eutectic phases can be expressed indirectly. In the case of DCC, the maximum $\Delta H$ is $-12.58 \mathrm{~J} / \mathrm{g}$, in comparison the minimum $\Delta H$ is $-11.12 \mathrm{~J} / \mathrm{g}$ in LFEC with $150 \mathrm{~A} / 10 \mathrm{~Hz}$. The $\Delta H$ of the remelting of eutectic phases reduces with an increasing current intensity. This illustrates that a decreasing eutectic phase and an increasing intra-granular alloy element are related with an increasing current intensity of electromagnetic field.

From the point of view of crystallography, the alloy elements can be form to interstitial solid solution or substitution solid solution according to the location of solution

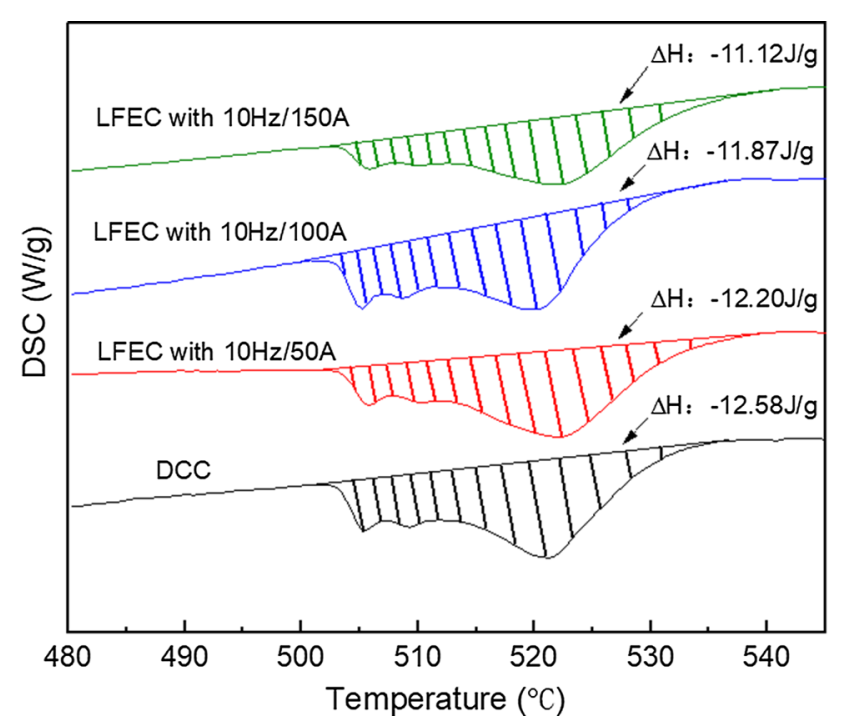

Fig. 9 DSC test of 2195 as-cast alloys by DCC and LFEC atom in the crystal lattice. No matter what type of solid solution, it would inevitably bring about the lattice distortion. The lattice distortion could be evaluated by the lattice parameters of $\alpha(\mathrm{Al})$ [23-25]. For 2195 alloy, $\mathrm{Cu}$ is the main alloy element. As the atomic size of $\mathrm{Cu}$ is smaller than $\mathrm{Al}$, when forming a substitution solid solution of $\mathrm{Cu}$, the lattice parameters of $\alpha(\mathrm{Al})$ will decrease. The larger $\mathrm{Cu}$ atom solid solution with intra-granular, the larger lattice distortion will be produced, and the greater changes in the lattice parameters of $\alpha(\mathrm{Al})$.

Figure 10 indicates the changes of the Bragg angles of $\alpha(\mathrm{Al})$ of 2195 as-cast alloy by DCC and LFEC on the four crystal faces of $\alpha(\mathrm{Al})$. The Bragg's law can be written as shown in Eq. (3):

$2 d \sin \theta=\lambda$,

where $d$ is the inter-planar distance; $\theta$ is the Bragg angle, and $\lambda$ is the wave length of $\mathrm{Cu} K \alpha$. The relation between the $d$ and $a$ is expressed as shown in Eq. (4).

$d=\frac{a}{\sqrt{h^{2}+k^{2}+l^{2}}}$

where $a$ is the lattice parameter, and $h, k, l$ are the crystal plane index.

Table 4 shows the lattice parameters and the variation of lattice parameter within four different crystal faces. It can be seen that on the four crystal faces, the lattice parameters decrease and the variation of lattice parameter increase with the increasing current intensity of electromagnetic field.

The average lattice parameters of $\alpha(\mathrm{Al})$ of 2195 as-cast alloys cast by DCC and LFEC are shown in Fig. 11. It could be proven that the solid solubility of alloy elements substantially increases with an increasing current intensity. This conclusion from XRD test is consistent with that from DSC test.

During non-equilibrium solidification, the alloy elements are released continuously from the growing grains to liquid phase. The liquid phase that containing high concentration of alloy elements will be remained at inter-dendritic when dendrites overlap with each other. Finally, numerous of alloy elements accumulate at grain boundaries forming eutectic phase with low smelting point. The serious segregated alloy elements tend to form various coarse precipitates. When applying LFEC, the heat transfer between the melt and the mold is intensified, resulting in deep under-cooling and fast solidification. Accelerated solidification rate means that the discharging of alloy elements would be limited. So a larger number of alloy elements atoms were retained with intragranular. Based on the classical Burton-Prim-Slichter (BPS) solution [26], the effective partition coefficient $k_{\mathrm{e}}$, can be described as shown in Eq. (5) 

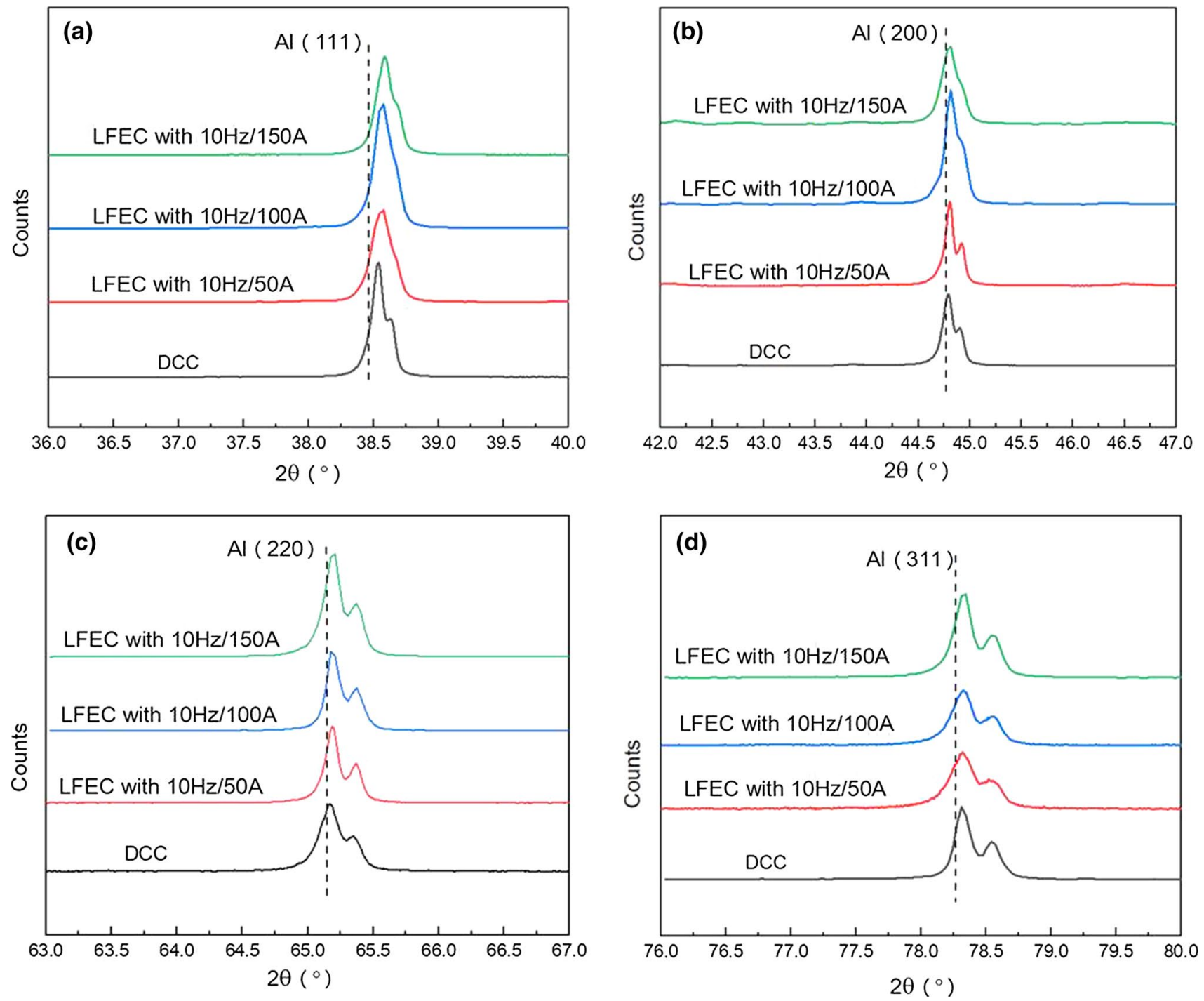

Fig. 10 XRD diffraction peaks of $\alpha(\mathrm{Al})$ of 2195 as-cast alloys cast by DCC and LFEC: a (111) crystal face; b (200) crystal face; c (220) crystal face; d (311) crystal face

$k_{\mathrm{e}}=\frac{\rho_{\mathrm{S}}}{\rho_{\mathrm{L}}}=\frac{k_{0}}{k_{0}+\left(1-k_{0}\right) e^{-R \delta / D}}$,

where $\rho_{\mathrm{S}}$ is the content of alloy elements in the solid phase, $\rho_{\mathrm{L}}$ is the content of alloy elements in the liquid phase, $k_{0}$ is the solute equilibrium partition coefficient, $R$ is the solidification velocity, $\delta$ is the thickness of boundary layer, and $D$ is the diffusion coefficient of alloy elements. The improved cooling intensity enhances the solidification velocity. Meanwhile, under a electromagnetic field the $\mathrm{Al}^{3+}, \mathrm{Cu}^{2+}, \mathrm{Li}^{+}$, $\mathrm{Mg}^{2+}$, and $\mathrm{Ag}^{+}$particles in the sump would be subjected to different Lorentz forces owing to their different rations of atomic masses and electric charges, which bring about the acutely irregular movement between the these particles [6]. This irregular movement trend of particles in boundary layer is far greater than that the diffusion trend. In the regard of energy, we think that low frequency electromagnetic field can supply higher energy to meet the need of crystal lattice distortion as more alloy element atoms in matrix. Therefore, the LFEC process can increase the intra-granular solid solubility of alloy elements.

\subsection{Effect of LFEC on Microstructure of 2195 Aged Alloys}

The microstructure of 2195 as-aged alloy after T6 treatment cast in conventional DCC process is shown in Fig. 12a, which consists of elongated, strip-like grains with $24.3 \pm 13.8 \mu \mathrm{m}$ in width aligned in the direction of extrusion, and coarse second-phases distributed along the grain boundaries. The average width of strip-like grains in the alloy cast by LFEC with $10 \mathrm{~Hz} / 150 \mathrm{~A}$ decreases to $13.1 \pm 10.1 \mu \mathrm{m}$ as 
Table 4 Lattice parameters of $\alpha(\mathrm{Al})$ of 2195 as-cast alloy cast by DCC and LFEC

\begin{tabular}{lllll}
\hline Miller indices & Casting condition & $2 \theta\left(^{\circ}\right)$ & $a(\mathrm{~nm})$ & $\Delta a(\mathrm{~nm})$ \\
\hline$(111)$ & DCC & 38.5382 & 0.40430 & -0.00070 \\
& $50 \mathrm{~A} / 10 \mathrm{~Hz}$ & 38.5777 & 0.40390 & -0.00110 \\
& $100 \mathrm{~A} / 10 \mathrm{~Hz}$ & 38.5777 & 0.40390 & -0.00110 \\
& $150 \mathrm{~A} / 10 \mathrm{~Hz}$ & 38.5862 & 0.40389 & -0.00119 \\
$(200)$ & $\mathrm{DCC}$ & 44.7862 & 0.40440 & -0.00060 \\
& $50 \mathrm{~A} / 10 \mathrm{~Hz}$ & 44.8022 & 0.40426 & -0.00074 \\
& $100 \mathrm{~A} / 10 \mathrm{~Hz}$ & 44.8147 & 0.40416 & -0.00084 \\
& $150 \mathrm{~A} / 10 \mathrm{~Hz}$ & 44.8147 & 0.40416 & -0.00084 \\
& $\mathrm{DCC}$ & 65.1622 & 0.40460 & -0.00040 \\
& $50 \mathrm{~A} / 10 \mathrm{~Hz}$ & 65.1862 & 0.40447 & -0.00053 \\
& $100 \mathrm{~A} / 10 \mathrm{~Hz}$ & 65.1756 & 0.40453 & -0.00047 \\
& $150 \mathrm{~A} / 10 \mathrm{~Hz}$ & 65.2087 & 0.40434 & -0.00066 \\
& $\mathrm{DCC}$ & 78.3097 & 0.40461 & -0.00039 \\
& $50 \mathrm{~A} / 10 \mathrm{~Hz}$ & 78.3222 & 0.40456 & -0.00044 \\
& $100 \mathrm{~A} / 10 \mathrm{~Hz}$ & 78.3222 & 0.40456 & -0.00044 \\
& $150 \mathrm{~A} / 10 \mathrm{~Hz}$ & 78.3427 & 0.40447 & -0.00053 \\
\hline
\end{tabular}

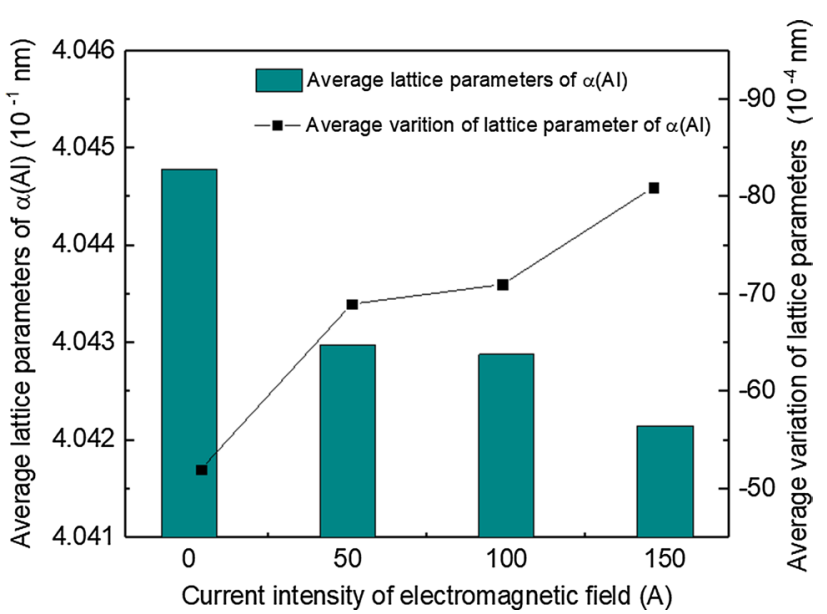

Fig. 11 Effects of current intensity on lattice parameters of $\alpha(\mathrm{Al})$ of 2195 as-cast alloy

shown in Fig. 12b. A large number of fine second-phases are found within the strips. It is evident that grain size are strongly affected by the presence of an electromagnetic field, which is obvious hereditary from casting to extruding and aging stage.

The precipitation phases which play important roles in strengthening the $\mathrm{Al}-\mathrm{Cu}-\mathrm{Mg}-\mathrm{Li}$ have been proved that is $\theta^{\prime}\left(\mathrm{Al}_{2} \mathrm{Cu}\right), T_{1}\left(\mathrm{Al}_{2} \mathrm{CuLi}\right), \delta^{\prime}\left(\mathrm{Al}_{3} \mathrm{Li}\right), \mathrm{S}^{\prime}\left(\mathrm{Al}_{2} \mathrm{CuMg}\right)$, particularly $\theta^{\prime}$ and $T_{1}$ phase $[27,28]$. In this study, the morphologies of $\theta^{\prime}$ phases and $T_{1}$ phases in 2195 alloy cast by DCC and LFEC after T6 treatment were observed by TEM as in Fig. 13. The statistical results of length and number density of precipitation phases are shown in Fig. 14. The lengths of $\theta^{\prime}$ phases and $T_{1}$ phases were categorized into various size groups. In the case of LFEC, the number density of $\theta^{\prime}$ phase that smaller than $200 \mathrm{~nm}$ increase in each size group, and the mean length of $\theta^{\prime}$ phase decreases from $137.9 \mathrm{~nm}$ to $115.7 \mathrm{~nm}$. The total number density of $\theta^{\prime}$ phase increases from 53.7 plates $/ \mu \mathrm{m}^{2}$ to 71.1 plates $/ \mu \mathrm{m}^{2}$. It is obvious from Fig. 14b that the length of $T_{1}$ phases that $50-100 \mathrm{~nm}$ is predominant, and there are a few $T_{1}$ phases whose length larger than $200 \mathrm{~nm}$. However, the size of major $T_{1}$ phase is $100-150 \mathrm{~nm}$ in the case of DCC. After applying LFEC with $150 \mathrm{~A} / 10 \mathrm{~Hz}$, the total number density of $T_{1}$ phase increases from 31.9 plates $/ \mu \mathrm{m}^{2}$ to 51.6 plates $/ \mu \mathrm{m}^{2}$, and the mean length of $T_{1}$ phase decreases from 150.3 to $97.9 \mathrm{~nm}$. In brief, the statistical data from the TEM photos show that main strengthening precipitation phases including $T_{1}$ phases and $\theta^{\prime}$ phases of 2195 aged alloys become finer, and exhibit higher density and more uniformly distributed under the influence of LFEC.

It is well known that the dislocations, grain boundary, and intra-granular alloy elements are related with the nucleation and precipitation for $T_{1}$ and $\theta^{\prime}$ phase, and the growth of $T_{1}$ and $\theta^{\prime}$ phase is of long term controlled diffusion mechanism relying on the atoms diffusion [28-32]. On the one hand, according to the discussion in Sect. 3.1, the effects of the refining grain are affected by a low frequency electromagnetic field. The effects could be passed genetically from the casting stage to aging stage, providing more nucleation sites for precipitates under the same extrusion conditions. On the other hand, the increased intra-granular solid solution of alloy elements provides the possibility for a larger amount of precipitation of precipitates. An increased number of $\mathrm{Cu}$ and $\mathrm{Li}$ atoms with intra-granular enhance super-saturation, which necessarily resulted in a larger amount of $T_{1}\left(\mathrm{Al}_{2} \mathrm{CuLi}\right)$ and $\theta^{\prime}\left(\mathrm{Al}_{2} \mathrm{Cu}\right)$ phases after aging. An increased number of $\mathrm{Mg}$ atoms with intra-granular reduce the solid solubility of $\mathrm{Li}$ in aged alloy, thus increasing the amount of lithium-containing precipitates. An increased number of Ag atoms with intragranular reduce the stacking fault energy [29]. It provides favorable conditions for the nucleation of the precipitation phases [16]. An increased number of super-saturated vacancies are generated with an increased number of $\mathrm{Mg}$ and $\mathrm{Ag}$ atoms with intra-granulars which lead to $\mathrm{Mg}$ and $\mathrm{Ag}$ atoms combine with vacancies [30]. The diffusion of $\mathrm{Li}$ and $\mathrm{Cu}$ atoms has been restricted by the combination of $\mathrm{Mg}, \mathrm{Ag}$ and vacancy [31]. Hence, under the mechanism of promoting the nucleation of precipitation phases and suppressing the growth of precipitation phases, a larger number of fine, distributed uniformly precipitation phases were obtained. 

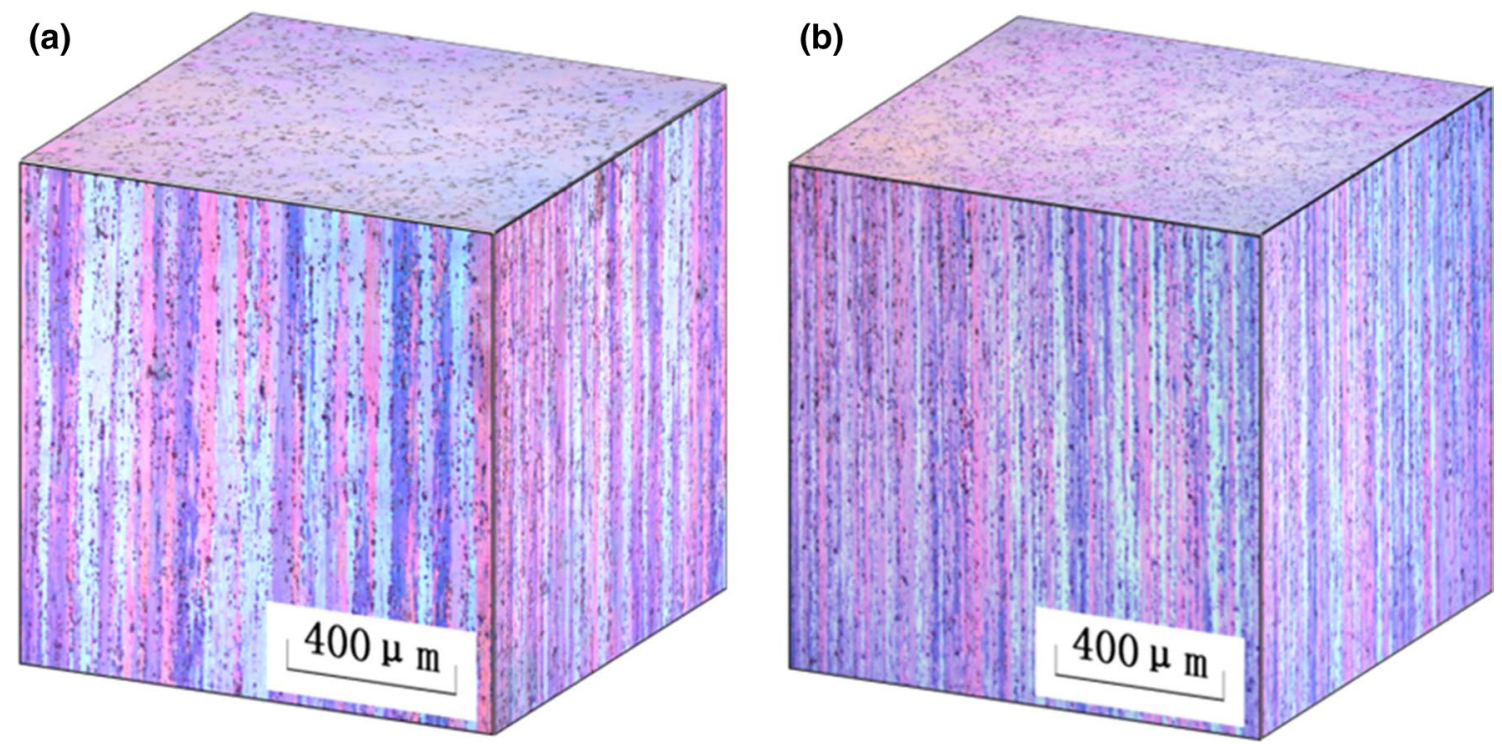

Fig. 12 Micrographs of 2195 as-aged alloys: a DCC, b LFEC with 10 Hz/150A

\subsection{Effect of LFEC on Tensile Properties of 2195 Aged Alloy}

Figure 15 illustrates the relation of the tensile properties of 2195 aged alloy on the current intensity and frequency. It is obvious that the yield strength and ultimate tensile strength of the aged alloys are all improved remarkably by LFEC. Maximum ultimate tensile strength (UTS) of $607.9 \mathrm{MPa}$ is obtained at LFEC with $150 \mathrm{~A} / 10 \mathrm{~Hz}$, which is $70.5 \mathrm{MPa}$ higher than that of DCC. At the same current intensity, the ultimate tensile strength of the aged alloys cast at $10 \mathrm{~Hz}$ is a bit higher than that at $20 \mathrm{~Hz}$. The increase in strength is accompanied by a decrease in elongation. The reasons for the poor tensile properties of 2195 aged alloys cast by DCC are mainly impute to the more casting defects caused in the casting stage and less precipitation phases precipitated in aging stage. However, the 2195 aged alloy cast by LFEC could obtain better tensile properties due to grain refining and precipitation strengthening.

\section{Conclusions}

The effects of LFEC on microstructure, solid solubility and mechanical properties of 2195 alloys have been investigated and compared with those of DCC. The following findings are obtained:

1. The microstructures of ingots were significantly refined by LFEC. The grain size of ingots undergo refinement from $219 \mu \mathrm{m}$ in DCC to $115 \mu \mathrm{m}$ in LFEC with 150 $\mathrm{A} / 10 \mathrm{~Hz}$.

2. The casting defects were effectively eliminated in the as-cast ingots by LFEC.

3. The solid solubility of alloy elements was significantly enhanced by LFEC, leading to highter density and more uniform distribution of $T_{1}$ phases and $\theta$ ' phases after T6 aging treatment.

4. The tensile properties of 2195 aged alloys were improved remarkably by LFEC. The maximum ultimate tensile strength of $607.93 \mathrm{MPa}$, the maximum yield strength of $521.13 \mathrm{MPa}$, and the corresponding elongation of $7.8 \%$ were acquired under the LFEC with $150 \mathrm{~A} / 10 \mathrm{~Hz}$. 

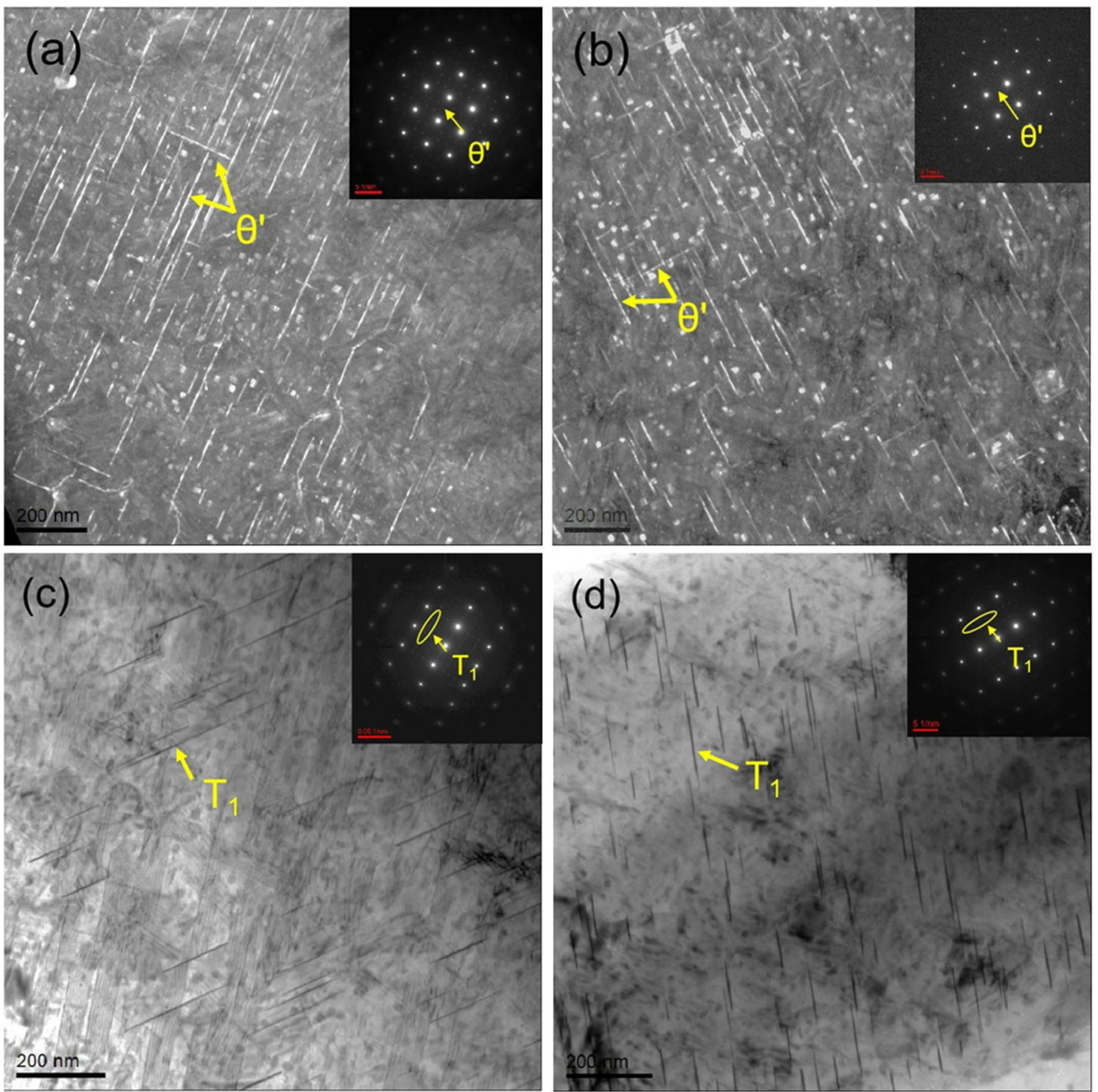

Fig. 13 TEM images of the alloy after T6 treatment: $\mathbf{a}, \mathbf{b}$ dark field image from $<001>\alpha, \theta^{\prime}$ phase; $\mathbf{c}, \mathbf{d}$ bright field image from $<112>\alpha, T_{1}$ phase; a, c DCC; b, d LFEC with $150 \mathrm{~A} / 10 \mathrm{~Hz}$ 

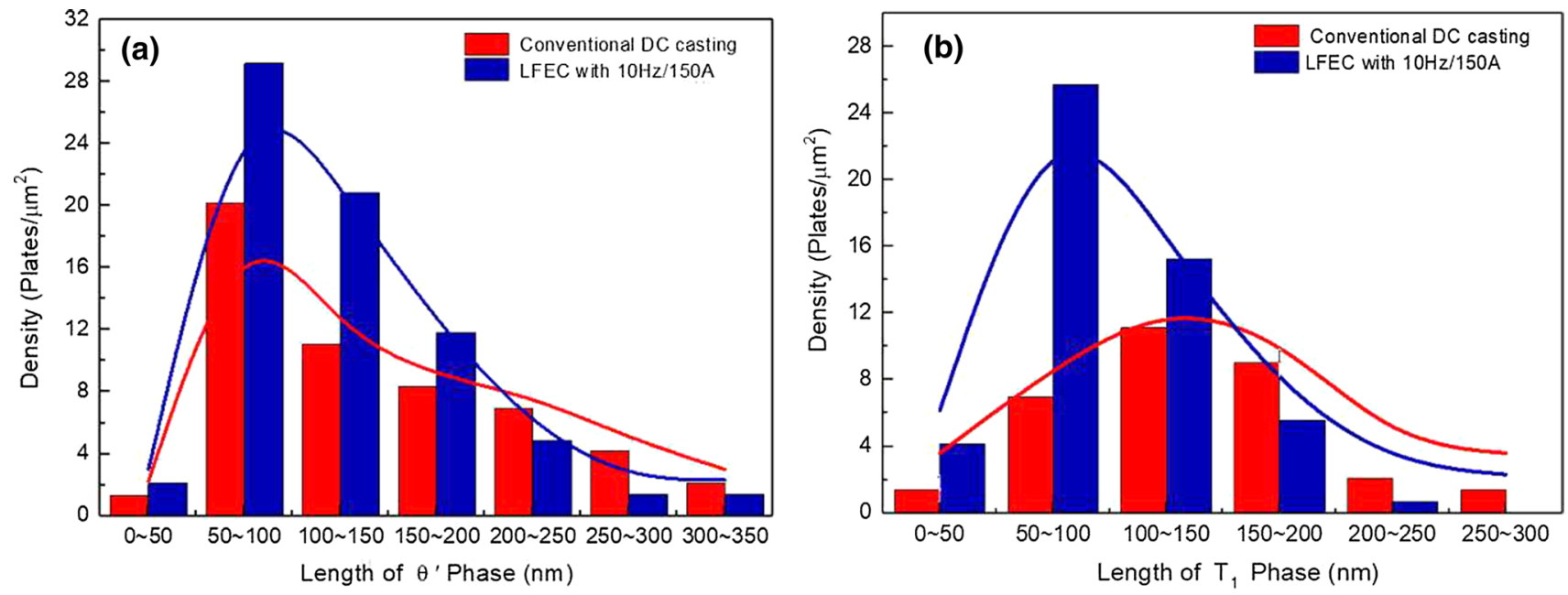

Fig. 14 Area density of strengthening precipitates in 2195 alloy after T6 treatment: a $\theta^{\prime} ; \mathbf{b} T_{1}$

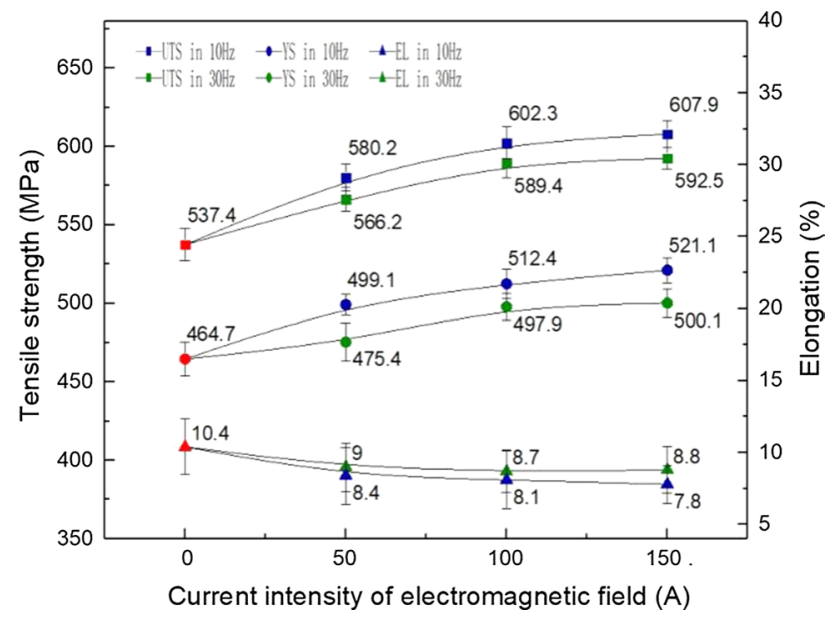

Fig. 15 Tensile properties of 2195 aged alloy cast by DCC and LFEC

Acknowledgements This work was financially supported by the National Key Research and Development Program of China (No. 2016YFB0300901), the National Natural Science Foundation of China (Nos. U1708251, 51574075, U1608252), the Liaoning Revitalization Talents Program (No. XLYC1807027) and the Fundamental Research Funds for the Central Universities (No. N180905010).

\section{References}

[1] J.C. Williams, E.A. Starke, Acta Mater. 51, 5775 (2003)

[2] E.J. Lavernia, N.J. Grant, J. Mater. Sci. 22, 1521 (1987)

[3] T.S. Srivatsan, E.J. Lavernia, J. Mater. Sci. Lett. 9, 888 (1990)

[4] M. Guérin, J. Alexis, E. Andrieu, C. Blanc, G. Odemer, Mater. Des. 87, 681 (2015)

[5] N. Akhtar, W. Akhtar, S.J. Wu, Int. J. Cast Met. Res. 28, 1 (2015)

[6] S.J. Li, T. Jiang, J.Y. Wang, L. Chen, B. Wei, Mater. Sci. Eng. A 757, 14 (2019)

[7] Q. Zhang, C.Y. Ban, J.Z. Cui, Q.X. Ba, G.M. Lu, Acta Phys. Sin. 52, 2642 (2003)
[8] S.H. Wang, S.J. Yang, C.F. Fang, J.Z. Wang, S.L. Dai, Trans. Nonferrous Met. Soc. China 19, 2083 (2009)

[9] J.Z. Cui, Z.Q. Zhang, Q.C. Le, Trans. Nonferrous Met. Soc. China 20, 2046 (2010)

[10] V. Charles, Metall. Trans. B 20, 623 (1989)

[11] Y.B. Zuo, Z.H. Zhao, J.Z. Cui, Adv. Mater. Res. 402, 850 (2011)

[12] X.J. Wang, H.T. Zhang, Y.B. Zuo, Mater. Sci. Eng. A 497, 416 (2008)

[13] D.D. Chen, H.T. Zhang, H. Jiang, J.Z. Cui, Mater. Sci. Eng. Technol. 42, 500 (2011)

[14] B.J. Zhang, J.Z. Cui, G.M. Lu, Mater. Sci. Eng. A 355, 325 (2003)

[15] E.L. Huskins, B. Cao, K.T. Ramesh, Mater. Sci. Eng. A 527, 1292 (2010)

[16] A. Deschamps, B. Decreus, F.D. Geuser, Acta Mater. 61, 4010 (2013)

[17] J. Dong, J.Z. Cui, F.X. Yu, Z.H. Zhao, Y.B. Zuo, J. Mater. Process. Technol. 171, 399 (2006)

[18] Y.B. Zuo, J.Z. Cui, H.T. Zhang, Mater. Sci. Eng. A 406, 286 (2005)

[19] Y.B. Zuo, H. Nagaumi, J.Z. Cui, J. Mater. Process. Technol. 197, 109 (2008)

[20] E. Liott, A. Lui, R. Vincent, S. Kumar, Z. Guo, Acta Mater. 70, 228 (2014)

[21] H.B. Xu, Q.Y Han, T.M. Thomas, Mater. Sci. Eng. A 473, 96 (2008)

[22] Q. Liu, R.H. Zhu, J.F. Li, Trans. Nonferrous Met. Soc. China 26, 607 (2016)

[23] C.L. Wang, S.Z. Lin, Y. Niu, Appl. Phys. A 76, 157 (2003)

[24] J. Su, F. Guo, H.S. Cai, L. Liu, J. Phys. Chem. Solids 131, 125 (2019)

[25] L.Y. Jiang, W.J. Huang, Mater. Sci. Eng. A 752, 145 (2019)

[26] J. Priede, G. Gerbeth, J. Cryst. Growth 285, 261 (2005)

[27] Y. Wang, G. Zhao, X. Xu, X. Chen, W. Zhang, Mater. Sci. Eng. A 727, 78 (2018)

[28] B. Jiang, F. Cao, H. Wang, D. Yi, Y. Jiang, Mater. Sci. Eng. A 740, 157 (2019)

[29] M. Murayama, K. Hono, Scr. Mater. 44, 701 (2001)

[30] B.P. Huang, Z.Q. Zheng, Acta Mater. 46, 4381 (1998)

[31] W.A. Cassada, G.J. Shiflet, E.A. Starke, Metall. Trans. A 22, 287 (1991)

[32] D. Tsivoulas, P.B. Prangnell, Acta Mater. 77, 1 (2014) 